\title{
MENINGKATKAN KECERDASAN NATURALIS ANAK MELALUI METODE PEMBELAJARAN OUTING CLASS PADA KELOMPOK B TK ASYIYAH X KOTA BENGKULU
}

\author{
Selfa Maryanti \\ selfamaryanti5@gmail.com \\ Nina Kurniah \\ ninakurniah@unib.ac.id \\ Yulidesni \\ yulidesni@gmail.com
}

\begin{abstract}
The purpose of this research is to improve the early child naturalist intelligence through outing class method in group B Tk Asyiyah X Bengkulu city. This research is Classroom Action Research (PTK). The subjects of this study were 15 children consisting of 7 men and 8 women. Research This class action is conducted with two cycles in each cycle consisting of three meetings. Data collection uses an observation sheet. Data analysis techniques use average and percentage values. The results of this study showed an increase in naturalist intelligence in children is evident from the average results of naturalist intelligence in the first cycle reached an average value of 2.8 with $70 \%$ classical completeness is in the criteria enough then in cycle II the average value of children reached 3, 3 with $82 \%$ classical clarity are in good criteria. It is suggested for the next researcher to use the outing class method in improving the naturalist intelligence of early child.
\end{abstract}

Keywords: Naturalist Intelligence; Method of Outing Class

\section{PENDAHULUAN}

Pendidikan pada anak usia dini (PAUD) merupakan pendidikan yang paling fundamental karena perkembangan anak dimasa selanjutnya akan sangat ditentukan oleh berbagai stimulasi bermakna yang diberikan sejak dini. Pendidikan anak usia dini saat ini sudah mulai diperhatikan oleh pemerintah Dalam undang-undang Nomor 20 Tahun 2003 Tentang Sistem Pendidikan Nasional Bab 1, pasal 1, Butir 14 dinyatakan bahwa "Pendidikan Anak Usia Dini adalah suatu upaya pembinaan yang ditujukan kepada anak sejak lahir sampai usia 6 tahun yang dilakukan melalui pemberian rangsangan pendidik untuk membantu pertumbuhan dan perkembangan jasmani dan rohani agar anak memiliki kesiapan dalam memasuki pendidikan lebih lanjut".

Anak Usia dini adalah sosok individu yang sedang menjalani suatu proses perkembangan yang sangat pesat bagi kehidupan anak tersebut selanjutya. Menurut Naeyc (dalam, Yuliani 2011: 6) bahwa anak usia dini berada pada rentang 0-8 tahun. Pada masa ini potensi anak mengalami perkembangan khususnya potensi kecerdasan, kecerdasan anak usia dini harus di stimulasi secara optimal agar berkembang sesuai dengan harapan.

Kecerdasan merupakan suatu hal yang diinginkan semua orang tua, namun disisi lain banyak orang tua yang kurang paham tentang kecerdasan yang dimiliki 
oleh anak, yang berakibat pada minimnya pengetahuan tentang cara mengembangkan kecerdasan jamak yang dimiliki oleh seorang anak. Kecerdasan bagi seseorang memiliki manfaat yang sangat besar dalam kehidupan dan bagi pergaulan dengan masyarakat, karena semakin tinggi kecerdasan seseorang maka akan semakin dihargai oleh masyarakat. Apalagi jika anak mampu berkiprah atau terlibat dalam menciptakan sesuatu yang baru yang bersifat fenomenal. Kemampuan seseorang dalam menciptakan sesuatu produk atau karya serta menyelesaikan masalah merupakan titik tekan teori kecerdasan jamak.

Menurut Gardner (Anita, 2011: 10) Kecerdasan jamak atau multiple intelegensi meliputi kecerdasan linguistik, kecerdasan logika matematika, kecerdasan kinestetik, kecerdasan visual-spasial, kecerdasan intrapersonal, kecerdasan interpersonal, kecerdasan musikal, kecerdasan naturalis, maupun kecerdasan eksistensial. kebanyakan orang tua mengagap bahwa anak yang cerdas apabila kecerdasan logika matematikanya tinggi, padahal sebetulnya semua anak itu cerdas hanya saja masingmasing anak mempunyai aspek kecerdasan yang berbeda-beda sehingga orang tua atau guru harus dapat memberikan stimulasi yang tepat dan sesuai degan tingkat perkembangan anak. Dalam pekembangan setiap anak tidak lepas dari lingkungan, membedakan benda-benda yang ada di sekitar anak, menyayangi lingkungan dan memelihara. Dalam kaitanya dengan hal ini maka perlu adanya pengembangan atau peningkatan aspek kecerdasan yang berhubungan dengan lingkungan yaitu Kecedasan naturalis.

Menurut Amstrong (Sujiono, 2010: 63) bahwa kecerdasan naturalis yaitu kecerdasan untuk mencintai keindahan alam melalui pengenalan terhadap flora dan fauna yang terdapat di lingkungan sekitar dan juga mengamati fenomena dan kepekaan/kepedulian terhadap lingkungan sekitar.

Kecerdasan naturalis mempunyai peran yang sangat besar dalam abad yang modern sekarang ini. Pengetahuan anak mengenai alam, hewan, tanaman dapat mengantarkan anak pada profesi yang sesuai dengan kecerdasan yang dimilikinya kelak, kecerdasan naturalis mempunyai peran yang sangat diperlukan dalam menjaga alam ini agar tetap dapat menjaga kelestarianya sehingga dapat dimanfaatkan oleh manusia.

Hasil observasi pada bulan Oktober 2016 di kelas B TK Asyiyah X Kota Bengkulu tahun ajaran 2016/2017 pada perkembangan kecerdasan naturalis belum berkembang dengan optimal. $\mathrm{Hal}$ inl dibuktikan dari 15 orang anak, hanya 3 orang anak yang masuk dalam kategori tuntas belajar dan sisanya yaitu 12 orang anak belum dapat dikatakan tuntas belajar terutama pada kecerdasan naturalis. Oleh sebab itu, untuk mendukung ketuntasan belajar anak pada kecerdasan naturalis perlu didukung oleh kegiatan-kegiatan yang berhubungan dengan kecerdasan naturalis seperti mengamati tumbuhan, binatang, dan merawat tanaman.

Ketidaktuntasan belajar anak disebabkan oleh kurangnya anak dalam mengenal dan membedakan jenis-jenis binatang, tidak mampu membedakan binatang yang serupa seperti sapi, kerbau, dan lembu, itik dengan bebek, anak tidak banyak mengenal nama-nama binatang. Selain itu anak tidak mengetahui ciri-ciri binatang unggas, serangga, ikan, dan hewan yang hidup di darat dan di air, dalam keterampilan dalam memelihara dan merawat binatang dan tumbuhan anak masih kurang mengerti. Selain hewan, anak-anak juga belum mengetahui tentang tumbuhan, nama-nama tumbuhan, cirri-ciri tumbuhan, dan bagian-bagian tumbuhan. Oleh sebab itu, untuk mendukung ketuntasan belajar anak pada kecerdasan 
naturalis perlu didukung oleh kegiatankegiatan yang berhubungan dengan kecerdasan naturalis seperti mengamati tumbuhan, binatang, dan merawat tanaman.

Selain itu ketidakoptimalnya kecerdasan naturalis anak juga disebabkan kegiatan pembelajaran yang dilakukan oleh guru sering dilakukan di dalam kelas yang hanya menggunakan gambar-gambar atau poster tanaman/binatang saja dalam melakukan kegiatan pembelajaran untuk mengembangkan kecerdasan naturalis sehingga dengan pembelajaran seperti itu anak akan mudah bosan serta pengalaman secara langsung tidak didapatkan oleh anak.

Mengingat sangat pentingnya kecerdasan naturalis pada anak usia dini untuk dikembangkan perlu adanya suatu metode yang harus dipersiapkan dan dilaksanakan oleh pendidik agar pengembangan kecerdasan naturalis pada anak berkembang secara optimal . salah satu metode yang dapat diterapkan dalam mengembangkan kecerdasan naturalis yaitu dengan menerapkan metode pembelajaran outing class.

Outing class adalah suatu kegiatan yang melibatkan alam secara langsung untuk dijadikan sebagai sumber belajar (Vera, 2012: 17). Metode Outing class merupakan upaya mengajak anak untuk lebih dekat dengan sumber belajar yang sesungguhnya, yaitu alam dan masyarakat. jadi, pembelajaran outing class lebih melibatkan anak secara langsung dengan lingkungan sekitar anak yang mengacu pada pengalaman dan pendidikan lingkungan yang sangat berpengaruh pada kecerdasan naturalis.

Pembelajaran outing class mengajak anak untuk beradaptasi dengan lingkungan, alam sekitar, serta dengan kehidupan masyarakat, bisa mengetahui pentingnya keterampilan hidup dan pengalaman hidup di lingkungan dan alam sekitar. pasalnya, pembelajaran outing class lebih menuntut peserta didik memahami kenyataan yang terjadi (vera, 2012: 20).

Berdasarkan latar belakang di atas perlu adanya peningkatan kecerdasan naturalis dengan pembelajaran yang disukai oleh anak. oleh sebab itu penulis akan melakukan penelitian dengan judul "meningkatkan kecerdasan naturalis anak melalui pembelajaran outing class"

Berdasarkan latar belakang dapat dirumuskan masalah menjadi: Apakah penggunaan metode outing class dapat meningkatkan kecerdasan naturalis dalam mengenal binatang dan tumbuhan pada anak kelompok B Tk Asyiyah $\mathrm{x}$ kota Bengkulu tahun 2016/2017.

Berdasarkan rumusan masalah di atas, maka tujuan dalam penelitian ini adalah Untuk meningkatkan kecerdasan naturalis dalam mengenal binatang dan tumbuhan pada kelompok B Tk Asyiyah $\mathrm{x}$ kota Bengkulu.

Menurut Gardner (dalam Yuliani, 2011: 194) kecerdasan naturalis adalah kemampuan mengenali dan mengatagorikan spesies yaitu flora dan fauna di lingkungan sekitar, mengenali keberadaan spesies, memetakan hubungan spesies. Sementara Amstrong (dalam, Yaumi 2013: 177) memberikan batasan tentang kecerdasan naturalis sebagai expertise in the recognition and classification of the numerous species-the flora and fauna-of an individua's enviroment Artinya, kecerdasan naturalis merupakan keahlian dalam mengenal dan mengklasifikasikan berbagai spesies termasuk flora dan fauna dalam suatu lingkungan.

Menurut Prasetyo (2009: 86) seseorang naturalis memiliki beberapa indikator diantaranya: Memiliki kepekaan terhadap alam dan lingkungan didalamnya, Memelihara binatang dan merawat tumbuhan, Mengetahui perubahan cuaca dan lingkungan alam, Mengelompokan objek yang ada di dalam sesuai dengan 
cirinya masing-masing, Mengenal dan mengelompokan berbagai mahkluk hidup yang berbeda, Berpetualang di alam terbuka dan suka bertanya tentang alam, Peduli dengan keadaan lingkungan alam beserta isinya, Memahami fenomena yang terjadi di alam, seperti siklus kehidupan makhluk hidup, Memahami bagaiman sesuatu di alam itu bekerja

\section{METODE PENELITIAN}

Penelitian Tindakan Kelas dapat di defenisikan sebagai suatu penelitian tindakan (action research) yang dilakukan oleh guru yang sekaligus sebagai peneliti dikelasnya atau bersama-sama dengan orang lain (kolaborasi) dengan jalan merancang, melaksanakan dan merefleksikan tindakan scara kolaboratif dan partisifatif yang bertujuan untuk memperbaiki atau meningkatkan mutu (kualitas) proses pembelajaran di kelasnya melalui suatu tindakan (treatment) tertentu dalam siklus (Kunandar, 2011: 44-45).

Pada penelitian ini, Penelitian Tindakan Kelas (PTK) dilakukan secara kolaboratif, dimana peneliti bertindak sebagai pelaksana tindakan dan guru yang bertindak mengamati proses jalanya tindakan. Penelitian tindakan kelas ini bertujuan untuk meningkatkan kecerdasan naturalis anak pada kelompok B Tk Asyiyah Kota Bengkulu tahun ajaran 2016/2017.

\section{Tempat dan waktu peneltitian}

Penelitian tindakan kelas ini akan dilaksanakan di kelas kelompok B Tk Asyiyah X Kota Bengkulu yang beralamatkan di Hibrida X Jl. Panti Asuhan Kota Bengkulu.

Penelitian ini akan dilaksanakan pada semester genap tahun ajaran 2016/2017. Jadwal rencana kegiatan penelitian ini berlangsung dari bulan Mei 2017 hingga Mei akhir 2017 yang dilakukan melalui dua siklus dengan tiga kali pertemuan setiap siklusnya.

\section{Subjek Penelitian}

Penelitian Tindakan Kelas ini akan dilaksanakan di Tk Asyiyah X Kota Bengkulu.
Subjek penelitian dalam penelitian tindakan kelas ini adalah anak-anak kelompok B Tk Asyiyah X Kota Bengkulu yang berjumlah 15 orang anak, terdiri dari 7 laki-laki dan 8 perempuan.

\section{Prosedur Penelitian}

Penelitian yang akan dilaksanakan adalah Penelitian Tindakan Kelas (PTK) menggunakan model penelitian Arikunto, dimana penelitian ini direncanakan dua siklus. Setiap siklus pada peneltian tindakan kelas terdiri dari empat tahap, yaitu: 1) perencanaan, 2) pelaksanaan, 3) observasi atau pengamatan, 4) refleksi. Adapun rancangan tindakan yang dilakukan yaitu:

\section{Perencanaan}

Kegiatan yang dlakukan dalam perencanaan mencakup aktivitas yang diorientasikan pada peningkatan kecerdasan Naturalis anak, adapun langkahlangkah sebagai berikut:

a. Pembuatan RPPM (terlampir)

b. Membuat RPPH (terlampir)

c. Menyusun instrumen penelitian (terlampir)

d. Menyiapkan media pembelajaran

\section{Tindakan/Pelaksanaan (Action)}

Tahap ini merupakan implementsi (pelaksanaan) dari perencanaan yang dibuat kemudian perencanaan tersebut dilaksanakn dalam kegiatan pembelajaran. Dalam pelaksanaan penelitian kegiatan mengacu pada rancangan kegiatan harian yang telah disepakati. Kekurangan dan kelemahan dalam pelaksanaan dapat diperbaiki.

\section{Observasi (Observing)}

Selama penelitian peneliti bersama teman sejawat melakukan observasi dan evaluasi. Observasi yaitu mengamati kecerdasan Naturalis anak pada waktu proses belajar mengajar berlangsung di dalam kelas maupun saat pelaksanaan pembelajaran outing class. Observasi dilakukan dalam rangka mengumpulkan data kecerdasan Naturalis anak melalui kegiatan outing class, data yang 
dikumpulkan pada tahap ini berisi tentang pelaksanaan tindakan yang sudah dibuat. Evaluasi dilakukan melalui penskoran dari pengamatan kegiatan outing class.

\section{Refleksi}

Setelah

dilakukan

evaluasi,

selanjutnya didiskusikan bersama,

komentar dan tanggapan serta penilaian semua dianalisis guna mengukur keberhasilan dan kegagalan atau kelemahan pada kecerdasan naturalis anak untuk mencari solusi untuk peningkatanya, dan bila siklus pertama ini belum dapat meningkatkan kecerdasan naturalis, maka perlu dilakukan siklus kedua.

\section{Teknik Pengumpulan Data}

Teknik pengumpulan data yang digunakan dalam penelitian tindakan kelas yaitu Observasi

Tabel 1. Aspek yang diteliti

\begin{tabular}{lccccccc}
\hline & & & SB & B & C & K & SK \\
\cline { 4 - 7 } N & Aspek & Indik & 5 & 4 & 3 & 2 & 1 \\
o & $\begin{array}{c}\text { yang } \\
\text { diteliti }\end{array}$ & ator & & & & & \\
& & & & & & & \\
& & & & & & &
\end{tabular}

1. mengena

I

binatang

dan

tumbuha

n.

Tabel 2. Kriteria Penilaian

\begin{tabular}{cc}
\hline $\begin{array}{c}\text { Skor } \\
\text { penilaian }\end{array}$ & Kriteria penilaian \\
\hline $\mathbf{5}$ & Sangat baik (SB) \\
\hline $\mathbf{4}$ & Baik (B) \\
\hline $\mathbf{3}$ & Cukup (C) \\
\hline $\mathbf{2}$ & Kurang (K) \\
\hline $\mathbf{1}$ & Sangat Kurang (SK) \\
\hline
\end{tabular}

Untuk memudahkan pengelolaan data maka kriteria penilaian tersebut dimodifikasi pada tabel 3 berikut
Tabel 3. Skor Penilaian

\begin{tabular}{|c|c|c|c|}
\hline $\begin{array}{c}\text { Skor } \\
\text { penilaian }\end{array}$ & $\begin{array}{c}\text { Konvers } \\
\text { i }\end{array}$ & Interval & $\begin{array}{c}\text { Kriteria } \\
\text { penilaia } \\
\mathbf{n}\end{array}$ \\
\hline 5 & $\begin{array}{l}80 \%- \\
100 \%\end{array}$ & $4,6-5$ & $\begin{array}{c}\text { Sangat } \\
\text { baik (SB) }\end{array}$ \\
\hline 4 & $\begin{array}{c}70 \%- \\
79 \%\end{array}$ & $3,6-4,5$ & Baik (B) \\
\hline 3 & $\begin{array}{c}60 \%- \\
69 \%\end{array}$ & $2,6-3,5$ & $\begin{array}{l}\text { Cukup } \\
\text { (C) }\end{array}$ \\
\hline 2 & $\begin{array}{c}50 \%- \\
59 \%\end{array}$ & $1,6-2,5$ & $\begin{array}{l}\text { Kurang } \\
\text { (K) }\end{array}$ \\
\hline 1 & $<50 \%$ & $0-1,5$ & $\begin{array}{l}\text { Sangat } \\
\text { Kurang }\end{array}$ \\
\hline
\end{tabular}

(SK)

\section{Teknik analisis data}

Teknik analisis data tentang kecerdasan naturalis anak dianalisis dengan uji rata-rata dan ketuntasan belajar, dengan rumusan sebagai berikut :

1) Uji Rata-Rata

Nilai rata-rata diperoleh dengan cara menjumlahkan semua nilai yang diperoleh anak kemudian dibagi dengan jumlah anak yang ada di kelas. Nilai rata-rata dapat dihitung menggunakan rumus :

Keterangan :

$$
\begin{aligned}
& X=\frac{\Sigma X}{\sum N} \\
& \mathrm{X}=\text { Nilai rata-rata } \\
& \Sigma \mathrm{X}=\text { Jumlah nilai semua } \\
& \text { siswa } \\
& \sum \mathrm{N} \quad=\text { Jumlah siswa }
\end{aligned}
$$

\section{Indikator Keberhasilan}

Penelitian tindakan kelas ini dikatakan berhasil apabila metode outing class mampu meningkatkan semua indikator kecerdasan naturalis anak yang diharapkan yaitu: menyebutkan nama-nama binatang dan tumbuhan, menyebutkan ciri-ciri 
binatang dan tumbuhan, menyebutkan bagian-bagian binatang dan tumbuhan dapat meningkat dan mencapai $75 \%$ dari setiap anak di dalam kelas.

\section{HASIL DAN PEMBAHASAN Hasil Penelitian}

Berikut ini adalah hasil penelitian yang didapatkan yang dipaparkan dalam tabel 4.

Tabel 4. Hasil observasi kecerdasan naturalis siklus I

\begin{tabular}{|c|c|c|c|c|}
\hline No & Nama & $\begin{array}{c}\text { Pertem } \\
\text { uan I }\end{array}$ & $\begin{array}{l}\text { Pertem } \\
\text { uan III }\end{array}$ & Ket \\
\hline 1 & AIA & 2,75 & 3 & Meningkat \\
\hline 2 & $\mathrm{Al}$ & 2,75 & 3 & Meningkat \\
\hline 3 & ASA & 2,75 & 3,25 & Meningkat \\
\hline 4 & AYA & 3,25 & 3,5 & Meningkat \\
\hline 5 & AKA & 2,25 & 3 & Meningkat \\
\hline 6 & BRI & 3 & 4 & Meningkat \\
\hline 7 & DW & 2,75 & 3,5 & Meningkat \\
\hline 8 & $\mathrm{EO}$ & 3 & 3 & Tetap \\
\hline 9 & FQN & 1,75 & 2,5 & Meningkat \\
\hline 10 & RF & 2,25 & 2,5 & Meningkat \\
\hline 11 & SSA & 2,25 & 3,25 & Meningkat \\
\hline 12 & VTA & 1,75 & 3 & Meningkat \\
\hline 13 & YYA & 3,5 & 3,5 & Tetap \\
\hline 14 & YP & 4 & 4 & Tetap \\
\hline 15 & ZVA & 3,25 & 3,75 & Meningkat \\
\hline \multicolumn{2}{|c|}{ Rata-rata } & 2,1 & 2,8 & Meningkat \\
\hline \multicolumn{2}{|c|}{$\begin{array}{l}\text { Ketuntasan } \\
\text { klasikal }\end{array}$} & $75 \%$ & $70 \%$ & Meningkat \\
\hline
\end{tabular}

Berdasarkan tabel 4 tersebut, Pada siklus I pertemuan pertama maupun ketiga hasil kecerdasan naturalis anak terus meningkat dengan rata-rata pada pertemuan pertama 2,1 dan pertemuan ketiga 2,8. Artinya dengan menggunakan metode outing class dapat meningkatkan kecerdasan naturalis anak. Sedangkan ketuntasan belajar anak secara klasikal terus meningkat dari pertemuan pertama $53,2 \%$ sampai dengan pertemuan ketiga mencapai $70,2 \%$.

Namun ketuntasan belajar anak tersebut belum mencapai indikator yaitu 75\% sehingga menurut peneliti dan teman sejawat perlu dilaksanakan siklus II.

Tabel 5. Hasil Analisis Data Observasi Aktivitas Guru Pada Siklus I

\begin{tabular}{|c|c|c|c|c|}
\hline \multicolumn{3}{|c|}{ Skor penilaian } & \multirow{2}{*}{$\begin{array}{l}\text { Rata } \\
\text {-rata }\end{array}$} & \multirow{2}{*}{$\begin{array}{c}\text { Kriteria } \\
\text { penilaian }\end{array}$} \\
\hline $\begin{array}{c}\text { Pertem } \\
\text { uan } 1\end{array}$ & $\begin{array}{c}\text { Pertem } \\
\text { uan II }\end{array}$ & $\begin{array}{l}\text { Pert } \\
\text { emu } \\
\text { an III }\end{array}$ & & \\
\hline 2,84 & 3,1 & 3,2 & 3,0 & Cukup \\
\hline
\end{tabular}

Berdasarkan Tabel 5 diperoleh data yang menunjukan bahwa rata-rata dari hasil observasi terhadap aktivitas guru pada siklus I yaitu pertemuan I sampai dengan pertemuan III yaitu 3,0 dengan katagori cukup.

Tabel 6. Hasil Observasi Keceradsan Naturalis Anak Siklus II

\begin{tabular}{|c|c|c|c|c|}
\hline No & Nama & $\begin{array}{c}\text { Pertem } \\
\text { uan I }\end{array}$ & $\begin{array}{c}\text { Pertem } \\
\text { uan III }\end{array}$ & Ket \\
\hline 1 & $\mathrm{AlA}$ & AIA & 3 & Meningkat \\
\hline 2 & $\mathrm{Al}$ & $\mathrm{Al}$ & 3,25 & Meningkat \\
\hline 3 & ASA & ASA & 3,25 & Meningkat \\
\hline 4 & AYA & AYA & 3,5 & Meningkat \\
\hline 5 & AKA & AKA & 3,25 & Meningkat \\
\hline 6 & BRI & BRI & 4 & Meningkat \\
\hline 7 & DW & DW & 3,5 & Meningkat \\
\hline 8 & EO & EO & 3,25 & Meningkat \\
\hline 9 & FQN & FQN & 2,5 & Meningkat \\
\hline 10 & RF & RF & 2,75 & Meningkat \\
\hline 11 & SSA & SSA & 3,25 & Meningkat \\
\hline 12 & VTA & VTA & 3 & Meningkat \\
\hline 13 & YYA & YYA & 3,75 & Meningkat \\
\hline
\end{tabular}




\begin{tabular}{ccccc}
\hline 14 & YP & YP & 4 & Tetap \\
\hline 15 & ZVA & ZVA & 3,75 & Meningkat \\
\hline Rata-rata & 3,0 & 3,3 & Meningkat \\
\hline $\begin{array}{c}\text { Ketuntasan } \\
\text { klasikal }\end{array}$ & $75 \%$ & $82,5 \%$ & Meningkat \\
\hline
\end{tabular}

Berdasarkan Tabel 6 tersebut, pada siklus II pertemuan pertama maupun ketiga hasil kecerdasan naturalis anak terus meningkat dengan rata-rata pada pertemuan pertama 3,0 dan pertemuan ketiga 3,3 Aspek kecerdasan naturalis anak yaitu mengenal binatang dan tumbuhan yang meliputi mengenal nama-nama binatang dan tumbuhan, mengungkapkan perilaku cara merawat binatang dan tumbuhan, menyebutkan bagian-bagian binatang dan tumbuhan, menyebutkan ciriciri binatang dan tumbuhan sudah berkembang secara maksimal hal ini terbukti dari anak yang sudah mampu menyebutkan nama-nama bintang/tumbuhan, berani memegang dan merawat langsung binatang dantumbuhan.

Ketuntasan belajar anak secara klasikal terus meningkat pada pertemuan pertama $75 \%$ dan pertemuan ketiga $82,5 \%$. Ketuntasan belajar anak tersebut telah mencapai indikator keberhasilan yaitu $75 \%$ sehingga menurut peneliti dan teman sejawat penelitian dilaksanakan sampai siklus II.

Tabel 7. Hasil Analisi Data Observasi Aktivitas Guru Pada Siklus II

\begin{tabular}{|c|c|c|c|c|}
\hline \multicolumn{3}{|c|}{ Skor penilaian } & \multirow{2}{*}{$\begin{array}{l}\text { Rata- } \\
\text { rata }\end{array}$} & \multirow{2}{*}{$\begin{array}{c}\text { Kriteri } \\
\text { a } \\
\text { penilai } \\
\text { an }\end{array}$} \\
\hline $\begin{array}{c}\text { Pertem } \\
\text { uan } 1\end{array}$ & $\begin{array}{c}\text { Pertem } \\
\text { uan II }\end{array}$ & $\begin{array}{l}\text { Pert } \\
\text { emu } \\
\text { an III }\end{array}$ & & \\
\hline 3,5 & 3,8 & 4,1 & 3,8 & Baik \\
\hline
\end{tabular}

Berdasarkan Tabel 7 diperoleh data yang menunjukan bahwa rata-rata hasil pengamatan terhadap aktivitas guru pada siklus II yaitu 3,8 dengan kriteria baik.
Dalam proses pembelajaran pada siklus II ini aktivitas yang dialami guru mengalami peningkatan dari pertemuan sebelumnya, seperti guru menyampaikan materi dengan lebih rinci, guru membimbing anak dengan baik, guru memberikan apresiasi kepada semua anak tanpa terkecuali, guru sudah bisa mengkondisikan kegiatan secara kondusif yang dilakukan baik di dalam kelas maupun di luar kelas.

Tabel 8. Hasil Perbandingan Peningkatan Kecerdasan Naturalis Siklus I dan II

\begin{tabular}{|c|c|c|c|c|}
\hline \multirow[t]{2}{*}{ No } & \multirow[t]{2}{*}{ Nama } & Siklus I & Siklus II & \multirow[t]{2}{*}{ Ket } \\
\hline & & $\begin{array}{c}\text { Pertemu } \\
\text { an } 3\end{array}$ & $\begin{array}{c}\text { Pertemu } \\
\text { an } 3\end{array}$ & \\
\hline 1 & $\mathrm{AlA}$ & 2,75 & 3 & Meningkat \\
\hline 2 & $\mathrm{Al}$ & 2,75 & 3,25 & Meningkat \\
\hline 3 & ASA & 2,75 & 3,25 & Meningkat \\
\hline 4 & AYA & 3,25 & 3,5 & Meningkat \\
\hline 5 & AKA & 2,25 & 3,25 & Meningkat \\
\hline 6 & BRI & 3 & 4 & Meningkat \\
\hline 7 & DW & 2,75 & 3,5 & Meningkat \\
\hline 8 & EO & 3 & 3,25 & Meningkat \\
\hline 9 & FQN & 1,75 & 2,5 & Meningkat \\
\hline 10 & RF & 2,25 & 2,75 & Meningkat \\
\hline 11 & SSA & 2,25 & 3,25 & Meningkat \\
\hline 12 & VTA & 1,75 & 3 & Meningkat \\
\hline 13 & YYA & 3,5 & 3,75 & Meningkat \\
\hline 14 & YP & 4 & 4 & Tetap \\
\hline 15 & ZVA & 3,25 & 3,75 & Meningkat \\
\hline & a-rata & 2,8 & 3,3 & Meningkat \\
\hline & $\begin{array}{l}\text { ntasan } \\
\text { ssikal }\end{array}$ & $70 \%$ & $82,5 \%$ & Meningkat \\
\hline
\end{tabular}

Berdasarkan tabel 8 hasil perbandingan peningkatan kecerdasan naturalis anak antara siklus I dan siklus II mengalami peningkatan yang baik. Hal ini terlihat pada setiap pertemuan dari siklus I 
dan siklus II yang mengalami peningkatan. Pada siklus I pertemuan ketiga rata-ratanya mencapai 2,8 sedangkan pada siklus II pertemuan ketiga rata-ratanya mencapai 3,3. Kecerdasan naturalis anak telah berkembang secara maksimal karena semua indikator yang meliputi aspek mengenal binatang dan tumbuhan yang meliputi mengenal nama-nama binatang dan tumbuhan, menyebutkan cara merawat binatang dan tumbuhan, anak sudah mampu menyebutkan bagian-bagian binatang dan tumbuhan, menyebutkan ciriciri binatang dan tumbuhan. Terdapat 4 orang anak yang berada pada kriteria Sangat baik, terdapat 11 orang anak yang mendapat kriteria Cukup, dan 1 anak berada pada kriteria Kurang.

\section{Pembahasan Penelitian}

Berdasarkan hasil data peneltian yang telah diuraikan di atas menunjukan bahwa dengan menggunkan outing class dapat meningkatkan kecerdasan naturalis anak dalam mengenal binatang dan tumbuhan. Hal ini sesuai dengan pendapat Vera (2012: 18) pembelajaran di luar kelas lebih melibatkan anak secara langsung dengan lingkungan sekitar mereka, sesuai materi yang diajarkan sehingga pembelajaran diluar kelas lebih mengacu pada pengalaman dan pendidikan lingkungan yang sangat berpengaruh pada kecerdasan anak.

Penggunaan metode outing class dalam meninkatkan kecerdasan naturalis dalam mengenal binatang dan tumbuhan memberikan kesempatan kepada anak untuk meningkatkan kesadaran, apresiasi, dan pemahaman anak terhadap lingkungan sekitar, menambah pengetahuan anak tentang alam sekitar terutama dalam mengenal binatang dan tumbuhan, menambah kecintaan anak terhadap alam sekitar, menambah kepedulian anak tentang alam sekitar.

Secara umum peningkatan kecerdasan naturalis dalam mengenal binatang dan tumbuhan anak antara siklus I dan siklus II mengalami peningkatan yang sangat baik. Hal ini disebakan karena pada setiap siklus dan pertemuan guru melakukan hal-hal yang dapat meningkatkan kecerdasan naturalis anak dengan mengajak anak langsung mengamati binatang dan tumbuhan, dengan mengamati secara langsung anak akan melihat, menyetuh, melakukan perawatan secara nyata kepada binatang dan tumbuhan sehingga pengalaman anak akan lebih berkesan dan kecintaan anak terhadap binatang dan tumbuhan akan semakin baik. Agar kegiatan outing class tidak bosan guru menyelingi kegiatan dengan bernyanyi bersama, nyanyi dan gerak, serta mengajak anak untuk tepuk semangat.

\section{PENUTUP}

\section{Simpulan}

Berdasarkan hasil penelitian yang telah dilakukan pada anak kelempok B Tk Asyiyah X Kota Bengkulu dapat disimpulkan bahwa:

1. Melalui metode outing class dapat meningkatkan kecerdasan naturalis pada aspek mengenal dan mengklasifikasikan yang meliputi mengenal nama-nama binatang/tumbuhan terlihat saat proses pembelajaran melihat langsung binatang dan tumbuhan anak secara spontan menyebutkan nama-nama binatang dan tumbuhan tersebut, pada aspek menunjukan perilaku cara merawat binatang/tumbuhan terlihat saat anak ikut terjun langsung memandikan, memberi makan binatang, serta menyiram dan memberi pupuk tumbuhan bunga, pada aspek menunjukan bagian-bagian hewan terlihat anak langsung menunjuk bagian binatang seperti kepala, tangan, kaki, sayap burung sedangkan untuk tumbuhan anak langsung menunjukan 
bagian batang, bunga, daun tumbuhan, pada aspek menyebutkan ciri-ciri binatang/tumbuhan terlihat saat anak menyebutkan perbedaan antara binatang satu dan binatang lain seperti suara, warna dan bentuk setiap burung/tumbuhan.

2. Pembelajaran dengan menggunakan metode outing class dapat meningkatkan kecerdasan naturalis anak dalam mengenal lebih dalam tentang binatang maupun tumbuhan hal ini terjadi karena guru memberikan pengenalan terhadap binatang dan tumbuhan dengan mengajak anak langsung sehingga saat disana anak mengamati secara langsung binatang dan tumbuhan meliputi mengenal nama-nama, mengungkapkan cara merawat binatang dan tumbuhan, menyebutkan bagian-bagian binatang dan tumbuhan, dan menyebutkan ciriciri binatan dan /tumbuhan selain itu agar anak tidak bosan dalam melakukan kegiatan pembelajaran outing class guru mengajak anak untuk bernyanyi dan diselingi dengan tepuk semangat, tepuk sate, secara bersamasama. Kecerdasan naturalis anak meningkat dari siklus I $70 \%$ menjadi $82 \%$ pada siklus II. Hasil tersebut menunjukan bahwa dengan menggunakan metode outing class dapat meningkatkan kecerdasan naturalis anak usia dini.

\section{Saran}

Terdapat saran yang dapat diberikan pada peneliti ini untuk beberapa pihak setelah merefleksi hasil dari pelaksanaan penelitian tindakan kelas ini, yaitu:

1) Bagi peneliti selanjutnya

Dalam penelitian ini diperoleh hasil bahwa kecerdasan naturalis anak usia dini pada aspek mengenal dan mengklasifikasikan binatang dan tumbuhan yang meliputi mengenal nama-nama, menunjukan perilaku cara merawat, menyebutkan bagian-bagian, dan menyebutkan ciri-ciri dapat berkembang dengan optimal, maka peneliti lebih lanjut dapat melakukan penelitian metode outing class untuk meningkatkan kecerdasan naturalis anak melalui aspek kecerdasan naturalis lainya.

\section{2) Bagi guru}

Metode outing class dapat digunakan untuk meningkatkan kecerdasan naturalis anak usia dini, agar kecerdasan naturalis dapat meningkat metode outing class harus disiapkan sebaik mungkin dengan mengenalkan anak secara langsung untuk mengamati binatang dan tumbuhan agar pembelajaran yang dilakukan tidak bosan guru bisa menyelingi dengan bernyayi bersama. Metode outing class merupakan kegiatan yang menyenangkan karena anak belajar langsung dari alam sehingga guru tidak berpatokan pada kegiatan pembelajaran lainya saja.

\section{DAFTAR PUSTAKA}

Aqib. (2009). Penelitian Tindakan Kelas Untuk Guru SD, SLB, dan TK. Bandung : CV Yrama Widya.

Arikunto, S. (2011). Penelitian Tindakan Kelas. Jakarta: Bumi Aksara.

Armstrong, T. (2013). Kecerdasan multiple di dalam kelas. Jakarta: PT Indeks.

Budiyono. (2004). Statistik Dasar untuk penelitian. Jakarta: PT Bumi Angkasa Geri Malang.

Emzir. (2011). Metodologi penelitian pendidikan kuantitatif dan kualitatif. Jakarta: Raja grafindo.

Hairunisa, A. (2006). Let's be smart. Bandung: Kaifa.

Hamzah. K. (2014). Mengelola kecerdasan dalan pembelajaran. Jakarta: bumi aksara 
Husamah. (2013). Pembelajaran luar kelas outoor learning. Jakarta: prestasi pustakarya.

Indriana, D. (2011). Ragam alat bantu mendia pengajaran. Jogjakarta: diva press.

Musfiroh, T. (2010). Pengembangan kecerdasan majemuk. Jakarta: universitas terbuka.

Nadiayu, R. (2012). Penerapan metode karya wisata berbasis lingkungan alam sekitar untuk mengembangkan kecerdasab naturalis anak kelompok a di tabriyatul athfal ar-ridho Malang. Skripsi.

Nawawi, H., Martini. (2006). instrumen penelitian bidang sosial. Yogyakarta: gadjah mada university press.

Vera, A. (2012). Metode mengajar anak diluar kelas. Yogyakarta: diva press

Yaumi, I. (2013). Pembelajaran berbasis kecerdasan jamak. Jakarta: prenada media grup. 